\title{
Microalgae for the production of lipid and carotenoids: a review with focus on stress regulation and adaptation
}

\author{
Xiao-Man Sun ${ }^{1}$, Lu-Jing Ren ${ }^{1,4^{*}}$, Quan-Yu Zhao ${ }^{2}$, Xiao-Jun Ji ${ }^{1,4}$ and He Huang ${ }^{2,3,4}$
}

\begin{abstract}
Microalgae have drawn great attention as promising sustainable source of lipids and carotenoids. Their lipid and carotenoids accumulation machinery can be trigged by the stress conditions such as nutrient limitation or exposure to the damaging physical factors. However, stressful conditions often adversely affect microalgal growth and cause oxidative damage to the cells, which can eventually reduce the yield of the desired products. To overcome these limitations, two-stage cultivation strategies and supplementation of growth-promoting agents have traditionally been utilized, but developing new highly adapted strains is theoretically the simplest strategy. In addition to genetic engineering, adaptive laboratory evolution (ALE) is frequently used to develop beneficial phenotypes in industrial microorganisms during long-term selection under specific stress conditions. In recent years, many studies have gradually introduced ALE as a powerful tool to improve the biological properties of microalgae, especially for improving the production of lipid and carotenoids. In this review, strategies for the manipulation of stress in microalgal lipids and carotenoids production are summarized and discussed. Furthermore, this review summarizes the overall state of ALE technology, including available selection pressures, methods, and their applications in microalgae for the improved production of lipids and carotenoids.
\end{abstract}

Keywords: Microalgae, Stress, Lipid, Carotenoids, Growth-promoting agents, Adaptive laboratory evolution

\section{Background}

With the increase of world population and energy demand, the search for renewable energy resources has become a critical issue. Microalgae have been recognized as a potential source of livestock feed, pharmaceuticals, and alternative fuels $[1,2]$. Microalgae can utilize one or more of their three major metabolic modes, photoautotrophy, heterotrophy, and mixotrophy, depending on light conditions and carbon availability $[3,4]$. In any of these modes, microalgae can provide an abundance of valueadded products, and more recently, interest has focused on lipids and carotenoids. The lipid content of microalgae is usually in the range of $20-50 \%$ of the cell dry weight,

\footnotetext{
${ }^{*}$ Correspondence: renlujing@njtech.edu.cn

${ }^{1}$ College of Biotechnology and Pharmaceutical Engineering, Nanjing Tech University, No. 30 South Puzhu Road, Nanjing 211816, People's Republic of China

Full list of author information is available at the end of the article
}

and can be as high as $80 \%$ under certain conditions [5]. Microalgal lipids are classified into two groups according to their carbon number. Fatty acids having 14-20 carbons were used for the production of biodiesel, and polyunsaturated fatty acids (PUFAs) with more than 20 carbon atoms were used as health food supplements especially docosahexaenoic acid (DHA) and eicosapentaenoic acid (EPA). In addition, microalgae are also known to produce carotenoids, which are responsible for light harvesting in photosynthetic metabolism. The absorbed energy can be transferred to chlorophylls by primary carotenoid like lutein, thus expanding the light-absorbing spectrum of microalgae [6]. Moreover, due to their anti-oxidant properties, carotenoids play an important role in alleviating certain cancers, premature aging, cardiovascular diseases, and arthritis [7, 8]. Furthermore, carotenoids are also often used as coloring agents and dyes because of their intrinsic color $[9,10]$. Among the well-known 
microalgal carotenoids, $\beta$-carotene, astaxanthin and lutein have the highest current market potential.

Microalgae can overproduce lipids or carotenoids under stress condition such as high salt, high light, or nutrient limitation $[11,12]$. For instance, lipid accumulation in Dunaliella sp. and Chlorella vulgaris was significantly increased under high-salinity stress, reaching $70 \%$ and $21.1 \%$, respectively $[13,14]$. Similarly, when salt concentration was increased from 4 to $9 \%, \beta$-carotene yield of Dunaliella salina was increased by 30 -fold [15]. However, stress-based strategies usually influence cell growth in an adverse way and also decrease the yield of desired products. Furthermore, the formation of reactive oxygen species (ROS) serves as an important component of the cellular responses to the stress condition. Consequently, an increase of biomass by two-stage processes and reduction of oxidative stress using phytohormones or antioxidants were developed to mitigate the negative aspects of stress-based strategies [16, 17]. Since such two-stage processes require complex control strategies, at least in theory, it would be easier to develop new production strains that are genetically capable of optimal growth under the inducing stress conditions. Accordingly, transcription factor engineering was actively developed to improve the production of lipids or carotenoids [18-20]. Moreover, a guideline was proposed for stress-driven adaptive evolution experiments. ALE has been widely utilized in bacteria and fungi to enhance their metabolic phenotypes or their tolerance to particular stress conditions $[21,22]$. By the same token, the ALE studies enjoy many advantages offered by the microalgae cells: (1) the majority of the microalgae have simple nutrient requirement; (2) it is easy to cultivate them in the laboratory and (3) it take shorter time for the microalgae cells to grow and their cultivation can span several generations in several months or weeks. In addition, compared to the random mutagenesis methods, ALE having sequential serial passages serves as a comparatively easy approach for the identification of the major mutations relevant with the improvement due to its low mutation frequency. Thus, it has recently been proven as an innovative and effective tool to improve the strain properties of the microalgae, and this field still is certainly open to innovations in the future.

The existing literature mainly focused on emphasizing the effect of various stresses on the production of lipids or carotenoids, or discussed the advantages of metabolic engineering for the improvement of microalgae strain [23-25]. However, in this review, we summarize recent works on manipulation of stress factors, including cultivation models and the development of novel stresstolerant microalgae strains, which is mainly focused on overcoming the negative effects of stress-based strategies.
More interestingly, we review the basics of ALE, including selection pressures and methods, and based on this, we summarize the practicability of different ALE approaches for optimizing the production of lipids and carotenoids in microalgae. In addition, the challenges and future perspective of stress regulation and -adaptation strategies were summarized.

\section{Manipulation of stresses by different cultivation modes}

Lower biomass and suffering oxidative injury serve as the two major consequences of cellular responses to the stress-based strategies. It has been well established that ROS can react instantaneously and nonspecifically with essential biological molecules, resulting in the alteration of cellular functions by leading to lipid peroxidation, protein oxidation, and DNA damage (Fig. 1). Therefore, increasing the biomass and maintaining ROS detoxification under stress conditions is paramount for the economically viable production of lipids or pigments.

\section{Two-stage cultivation strategies Abiotic stresses}

To resolve the conflict between cell growth and the production of valuable molecules, a general countermeasure is two-stage cultivation strategy, dedicating the first stage with optimum growth conditions to gain the maximum biomass production, while reserving the second process for the accumulation of lipids or carotenoids under various stress conditions (Fig. 2). In general, lipids can be over-produced by microalgae by introducing stress at the second cultivation stage, for instance nitrogen depletion [26], light intensity [27], temperature [28], salt concentration [29], or iron concentration in the second stage [30]. In one approach, microalgae were grown under red LEDs $(660 \mathrm{~nm})$ in the first phase to obtain the maximum biomass production, and stressed in the second phase using green LEDs $(520 \mathrm{~nm})$ to stimulate lipid accumulation [31]. Similarly, a two-stage culture strategy was implemented to increase the biomass of Isochrysis galbana under sufficient nutrients, followed by cultivation under low-salt stress, which increased the lipid content from 24 to $47 \%$ [32]. In Nannochloropsis oculata, the lipid yield obtained in a two-stage process was 2.82-times over that being generated through the conventional single-stage batch cultivation [33].

Compared to lipids, the algae-based production of pigments is well established at a large scale. Two-stage processes can be more readily scaled up and are amenable to outdoor production [30]. High-light stress is the best induction technique for the overproduction of carotenoids in a number of species. Increasing the light intensity resulted in an enhanced lutein productivity of 


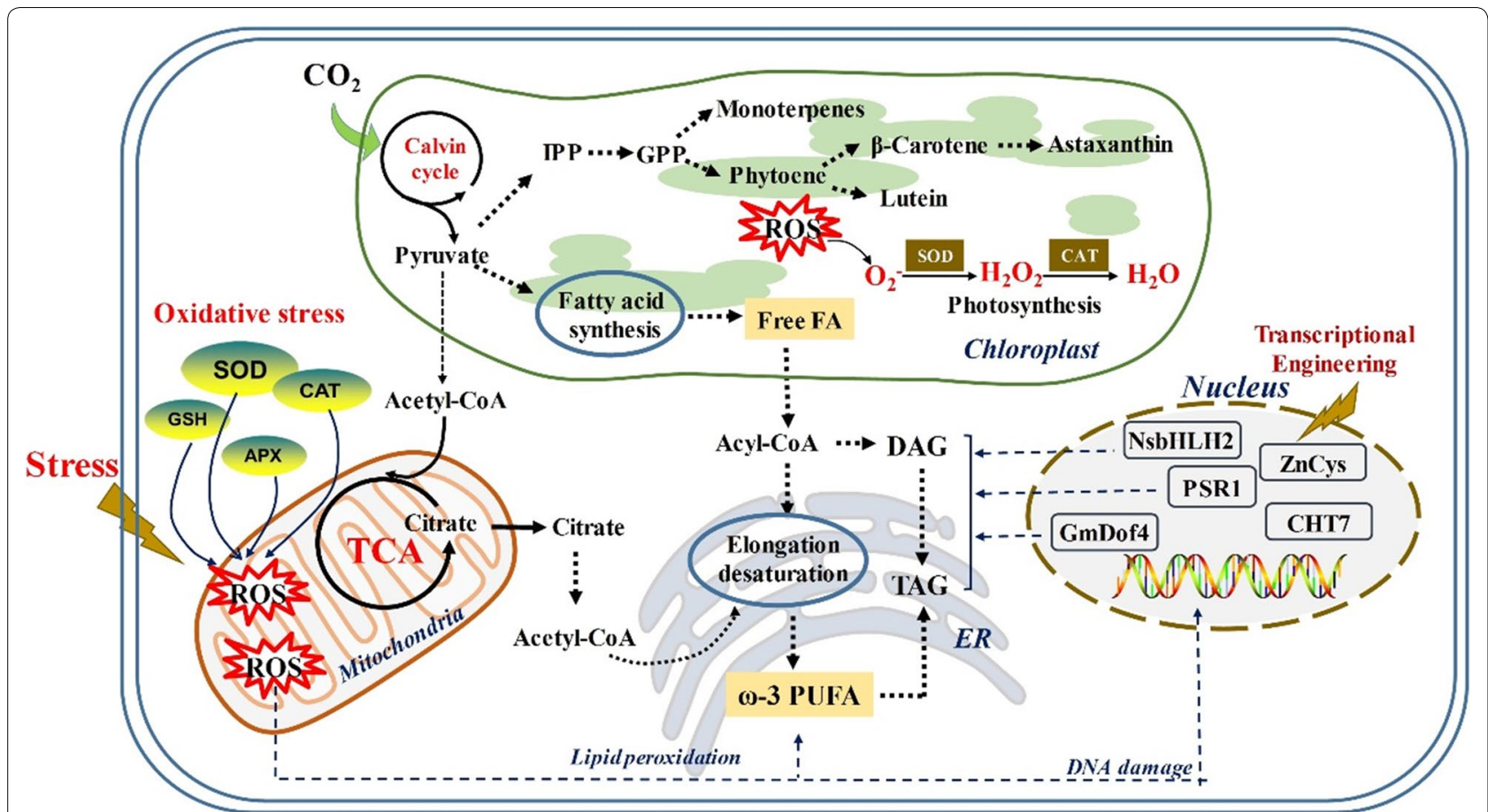

Fig. 1 Oxidative damage under stress conditions and manipulation of stresses by transcriptional engineering. GSH glutathione, ER endoplasmic reticulum

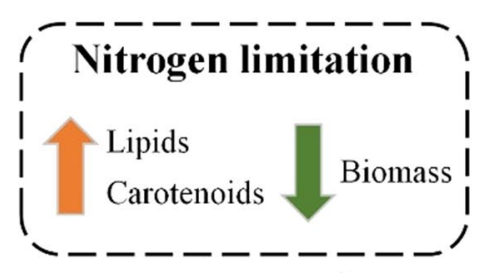

Phase I High nitrogen $\hookrightarrow$ Biomass $\uparrow$

Phase II Low nitrogen $\leftrightharpoons$ Astaxanthin $\uparrow$

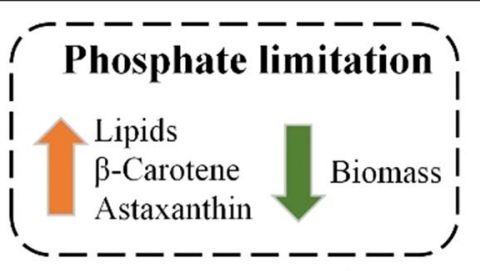

Phase I High phosphate $\leftrightharpoons$ Biomass $\uparrow$

Phase II Low phosphate $\leftrightharpoons$ DHA $\uparrow$
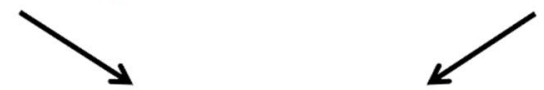

\section{Two-stage cultivation strategies}

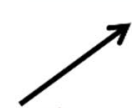

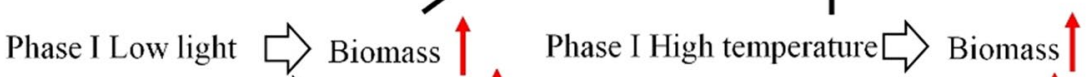

Phase II High light $\leftrightharpoons$ Astaxanthin $\uparrow$ Phase II Low temperature $\leftrightharpoons$ PUFAs $\uparrow$

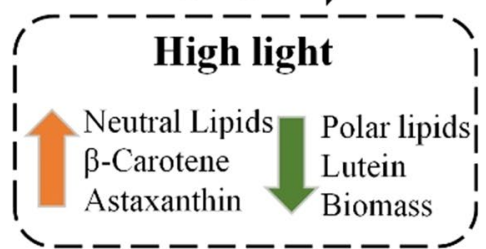

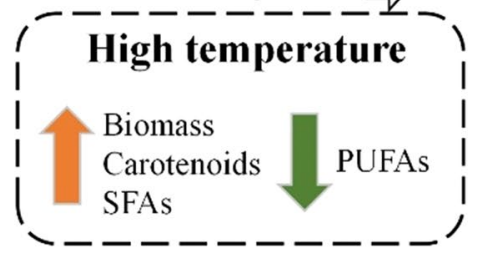

r

Phase I Low salinity $\leftrightharpoons$ Biomass $\uparrow$ Phase II High salinity $\Rightarrow$ Lipids $\uparrow$

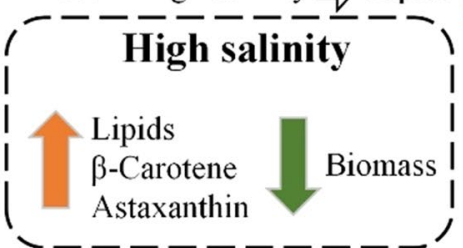

Fig. 2 Effects of typical nutrient- and environmental stresses on the production of lipid and carotenoids in microalgae, and the resulting two-stage cultivation strategies used to overcome the biomass limitation imposed by the stress conditions 
$3.6 \mathrm{mg} \mathrm{L}^{-1}$ day $^{-1}$ in Desmodesmus sp., as well as a maximum $\beta$-carotene production of $30 \mathrm{pg} \mathrm{cell}^{-1}$ day $^{-1}$ in $D$. salina $[34,35]$. The two-stage strategy with light stress has been successfully performed for carotenoids production, but it is most commonly applied in the production of astaxanthin. A richer astaxanthin product (4\% of dry biomass) was yielded through a two-stage cultivation system in conjunction with light stress, among which a final astaxanthin productivity of $11.5 \mathrm{mg} \mathrm{L}^{-1}$ day $^{-1}$ was obtained [36]. Such sequential manufacturing system is also applied for the manufacturing of the astaxanthin through the microalga Haematococcus pluvialis [37, 38]. Similarly, a two-stage process with a switch in light intensity was also applied to enhance the lutein productivity of Scenedesmus obliquus [39]. In a recent study, an innovative staged cultivation method was proposed to overcome the limiting factors associated with the growth of $H$. pluvialis, which resulted in a 1.16-fold increase in biomass concentration [40]. Moreover, temperature also has strong effect on carotenoids production by influencing the enzymes involved in carotenoids biosynthesis. It has been reported that high temperatures led to an increase of lutein accumulation in Muriellopsis sp. and Scenedesmus almeriensis. The effects of day- and night-time temperature on $H$. pluvialis were studied, and the results indicated that raising the day- or night-time temperature could stimulate accumulation of astaxanthin during the night up to a temperature of $28^{\circ} \mathrm{C}$ [41]. However, insufficient work has been done on carotenoids production using two-stage process combined with high-temperature stress.

\section{Autotrophy/heterotrophy regimes}

Interestingly, a novel sequential heterotrophy-dilutionphotoinduction process was developed to prevent the reduction of biomass. In this approach, microalgae are grown heterotrophically first to obtain a high cell density, after which the culture medium is diluted to a suitable concentration. Subsequently, it was transferred to a brightly lit environment for photoinduction. A novel approach called "sequential heterotrophy-dilution-photoinduction" was developed, in which the lipid content of Chlorella vulgaris, Chlorella pyrenoidosa and Chlorella ellipsoidea was increased by $84.57 \%, 70.65 \%$, and $121.59 \%$, respectively [42]. Similarly, a maximum lipid content of $50.5 \%$ (of dry weight) was achieved using heterotrophy-photoinduction cultivation regime, representing a $69.3 \%$ increase over that of single heterotrophic cultivation [43]. More importantly, proteomic analysis revealed that ATP synthase and acyl-CoA dehydrogenase were down-regulated, while glucose-1-phosphate adenylyltransferase and malate dehydrogenase were markedly up-regulated [43]. Furthermore, this system has been utilized for biomass and astaxanthin production in $H$. pluvialis [44]. Recently, using a two-stage heterotrophy/ photoinduction culture strategy, the lutein productivity of Scenedesmus incrassatulus was improved by $60 \%$ in comparison with the autotrophic fed-batch culture [45]. The productivity of total metabolites and lipids can be increased using these strategies in the same biomass obtained at the end of the growth cycle. However, such two-stage cultivation strategies can consume more energy than comparable one-stage systems, especially if harvesting the biomass is essential for entry into the second fermentation stage [46]. Moreover, it is difficult to determine the timepoint of fermentation exactly, which results in the instability of the production.

\section{Supplementation of growth-promoting agents Regulating biosynthetic pathways}

In addition to two-stage cultivation strategies, phytohormones are also able to induce the production of lipid or pigments in microalgae by adjusting the internal biochemical pathways [16], which serves as growth-promoting agents within the single-stage cultivation process (Table 1). Auxins play an important role in the growth of plants and microalgae by regulating cell division and expansion [47]. In S. obliquus, the biomass yield was increased by 1.9-2.5-folds through addition of $10^{-5} \mathrm{M}$ Indole-3-acetic acid (IAA) and diethyl aminoethyl hexanoate (DAH), respectively, whereby the lipid content of microalgae grew to $100 \mathrm{mg} / \mathrm{g}$-DCW due to the impact of both phytohormones [48]. Moreover, improved growth and lipid accumulation under the impact of the IAA and corresponding analogs has also been reported in C. vulgaris [49], C. pyrenoidosa and Scenedesmus quadricauda [50].

Moreover, auxin treatments combined with stress conditions can further stimulate cell growth and the lipid production of microalgae [51]. Recently, under stress induced by a $50 \%$ nitrogen limitation, the highest biomass concentration and lipid productivity were achieved by treating Chlorella sorokiniana with IAA [52]. Furthermore, the up-regulated expression of $r b c L$ (ribulose 1, 5-bisphosphate carboxylase/oxygenase) and $a c c D$ (acetyl-CoA carboxylase) genes suggested that IAA can regulate the certain metabolic pathways related to carbon fixation and lipid biosynthesis [50]. In another study, Liu et al. [53] founded that 1-naphthaleneacetic acid (NAA) exhibited a more pronounced promoting effect on cell growth and lipid productivity of $C$. vulgaris than abscisic acid (ABA) and 2,4-dichlorophenoxyacetic acid (2,4D), and further analysis showed that NAA treatment can up-regulate the $K A S 1$ and $S A D$ genes expression which regulated fatty acids biosynthesis in microalgae. It has been reported that the stimulated effect of IAA 
Table 1 Manipulation of stress factors by phytohormones

\begin{tabular}{|c|c|c|c|c|}
\hline Species & Phytohormones & Stress & Performance & References \\
\hline Scenedesmus quadricauda & $\mathrm{ABA}$ & Nitrogen-deficient stress & The dry biomass yield was increased up to 2.1 fold & {$[56]$} \\
\hline Chlorella sorokiniana & IAA, DA-6 & Nitrogen-limited stress & $\begin{array}{l}\text { Growth and lipid accumulation were both promoted } \\
\text { and phytohormones enhances CAT and SOD enzyme } \\
\text { activities }\end{array}$ & {$[52]$} \\
\hline Nannochloropsis oceanica & $\mathrm{ABA}, \mathrm{CKs}$ & Nitrogen-depletion stress & $\begin{array}{l}\text { Exogenous CKs stimulate cell-cycle progression, but } \\
\text { ABA acts as both an algal growth repressor and a } \\
\text { positive regulator in response to stresses }\end{array}$ & {$[70]$} \\
\hline Chlamydomonas reinhardtii & IAA, GA 3, KIN, TRIA, ABA & Nitrogen-limited stress & $\begin{array}{l}\text { All five of the tested phytohormones significantly } \\
\text { increased microalgal growth, particularly in nitrogen- } \\
\text { limited media }\end{array}$ & {$[54]$} \\
\hline Chlamydomonas reinhardtii & ABA & Osmotic and salt stresses & $\begin{array}{l}\text { ABA treatment markedly reduced ROS generation } \\
\text { and enhanced gene expression of the antioxidant } \\
\text { enzymes }\end{array}$ & [58] \\
\hline Chlorella vulgaris & IAA, PAA, IBA, NAA & Oxidative stress & $\begin{array}{l}\text { All auxins can suppress lipid peroxidation and hydro- } \\
\text { gen peroxide accumulation }\end{array}$ & {$[49]$} \\
\hline Chlamydomonas reinhardtii & $\mathrm{ABA}$ & Oxidative stress & Addition of ABA improve the growth of this alga & {$[67]$} \\
\hline
\end{tabular}

on microalgae growth was more obvious under nitrogen limitation condition [54]. A novel stepwise strategy was developed to improve both growth and lipid production in Dunaliella tertiolecta, in which 2, 4-D addition at the first phase improved biomass productivity by $40 \%$, and then salt stress was applied to increase lipid content from 24 to $70 \%$ [55]. ABA can enlarge cell diameter and promote cell division to alleviate growth limitation caused by stress condition, although it forces microalgae cell to enter the resting phase earlier. For example, exogenous addition of abscisic acid (ABA) increased the biomass and SFA content of S. quadricauda up to 2.1-fold and $11.17 \%$ compared to nitrogen-deficient cells, respectively [56], whereby exogenous ABA also improved the cells' tolerance to higher salinity and osmotic stress $[57,58]$.

Similarity, phytohormones also can enhance carotenoids production by working as metabolism enhancers. After treatment with methyl jasmonate and gibberellin A3, $H$. pluvialis cells accumulated more astaxanthin than the control, which might be due to the up-regulation of $\beta$-carotene ketolase genes [59]. Gao et al. [60, 61] reported that the astaxanthin productivity of $H$. pluvialis can be increased by supplementing 25 or $50 \mathrm{mg} / \mathrm{L}$ jasmonic acid (JA) and salicylic acid (SA), and further analysis found that the promoting mechanisms were dose dependent. For instance, $25 \mathrm{mg} / \mathrm{L} \mathrm{JA}$ treatment exhibited greater effect on the expression of $p d s, c r t \mathrm{R}-\mathrm{B}$ and $l y c$ genes, while $50 \mathrm{mg} / \mathrm{L} \mathrm{JA}$ impacted the expression of ipi1, ipi-2, psy, crt $\mathrm{R}-\mathrm{B}$ and $c r t \mathrm{O}$ genes more significantly. In addition, under $5 \mathrm{mg} / \mathrm{L}$ fulvic acid induction, the astaxanthin content of $H$. pluvialis was increased by $86.89 \%$, in which the transcription levels of phytoene desaturase (PDS), lycopene cyclase gene (LCY) and $\beta$-carotene hydroxylase (CHY) genes was increased by 69.3-, 1.2-, and 18.1-fold, respectively [62]. In conclusion, addition of phytohormones strategy is a sustainable and economical strategy, and it can easily be applied for large-scale production of lipids or carotenoids.

\section{Alleviating oxidative stress}

It is worth mentioning that increasing experimental evidence links phytohormones to a reduction of oxidative stress. ROS are unavoidable by-products of many metabolic pathways that are active under stress conditions [63]. The cellular ROS of the highest importance include the hydrogen peroxide $\left(\mathrm{H}_{2} \mathrm{O}_{2}\right)$, superoxide anion $\left(\mathrm{O}_{2}{ }^{-}\right)$, peroxyl radicals $\left(\mathrm{LOO}^{-}\right)$, lipid hydroperoxides $(\mathrm{LOOH})$, and hydroxyl radical $\left({ }^{-} \mathrm{OH}\right)$ [64]. To scavenge ROS, microalgae have evolved enzymatic (SOD superoxide dismutase, $C A T$ catalase, $A P X$ ascorbate peroxidase) as well as non-enzymatic (ascorbate, glutathione) antioxidant defense mechanisms (Fig. 1). Nevertheless, when cells are exposed to stress, balance between the ROS production and elimination is disturbed. This results in the damage via the oxidation of cellular components, i.e., "oxidative stress" [65].

Increasing evidences suggested that phytohormones can regulate the oxidative stress response of microalgae [66 换一个新的]. For example, the activities of CAT and APX were markedly increased in response to oxidative stress in ABA-treated Chlamydomonas reinhardtii [67]. Likewise, addition of ABA can enhance the gene expression of the APX and CAT for mitigating oxidative stress generated by osmotic and salt stresses [58]. Chokshi et al. [68] and Wu et al. [69] showed that the phytohormone content was significantly higher in nitrogen-depleted microalgae cells than in nitrogen-replete condition, likely because intracellular oxidative species 
and phytohormones interact with each other to fine-tune the oxidative stress response. In the oleaginous microalga Nannochloropsis oceanica, Lu et al. [70] also found that the key genes involved in the ABA biosynthesis pathway were up-regulated in nitrogen-starved cells, indicating the function of the ABA on the release of the stress damage. Moreover, phytohormones are often associated with the signaling induced by ROS. For instance, the $\mathrm{H}_{2} \mathrm{O}_{2}$ and auxin create the antagonistic impacts over the gene activation and cell cycle [71]. $\mathrm{H}_{2} \mathrm{O}_{2}$ treatment can suppress the expression of auxin-responsive genes via mitogenactivated protein kinase activation [72]. Recently, Khasin et al. [73] suggested that ABA can participate in ROS signaling pathways and alter ROS production and scavenging, which is a potential new mechanism for the regulation of oxidative stress.

In fact, antioxidants have been used more extensively than phytohormones to promote the scavenging of intracellular ROS in microalgae. But almost, all of such studies were focused on PUFAs production, which might be for the reason that the unsaturated double bonds in PUFAs are chemically more prone to oxidation. For instance, DHA productivity of Crypthecodinium cohnii was increased from 20 to $44 \%$ by adding the sesamol [74]. Additionally, Gaffney et al. [75] enhanced the antioxidant ability of the microalgae Schizochytrium sp. through the facilitations of the flaxseed oil. Moreover, with the treatment of ascorbic acid, DHA yield of Schizochytrium sp. was increased from 26.5 to $38.3 \mathrm{~g} / \mathrm{L}$, which accompanied with the lower ROS levels and higher antioxidant capacity [17]. Supplementing butylated hydroxytoluene or propyl into the media led to the increase of lipid and biomass levels in the thraustochytrids, with propyl gallate being the more effective of the two antioxidants [76]. Therefore, the combination of antioxidants and stress-based strategies appears to be a practical cultivation mode to improve the growth of microalgae.

\section{Co-cultivation of microalgae with the growth-promoting bacterium}

For the reduction of the production cost and improvement of lipid productivity, microalgae should be simultaneously cultivated in low-cost cultivation systems, such as co-cultivations [77]. In the mixed culture, microalgae could act as an oxygen generator for the bacteria while the bacteria provided $\mathrm{CO}_{2}$ to microalgae [77]. Moreover, certain class of bacteria can stimulate microalgae growth by producing growth-promoting factors, including trace metals, vitamins, phytohormones, and chelators [77]. Do Nascimento et al. [78] showed that inoculation with the bacterium Rhizobium strain resulted in increments of up to $30 \%$ in lipids accumulation of the oleaginous microalgae Ankistrodesmus sp., and this stimulation effect was apparently related to indol 3-acetic acid and/or vitamin $\mathrm{B}_{12}$ produced by the bacterium. Many studies reported that the growth of $C$. vulgaris was significantly enhanced in the presence of Azospirillum brasilense that a bacterium can produce the plant hormone indole-3-acetic acid [79, 80]. When microalgae Chlorella sp. was co-cultured with the growth-promoting bacterium Azospirillum sp., the lipid content was greatly increased from $6.76 \%$ under monoculture to $32.94 \%$ under co-culture system [81]. However, although microalgae-bacteria co-cultivation has been comprehensively described, the positive effects of bacterial on lipid production are mostly speculative. In the future, it is needed to select and characterize more growth-promoting bacteria for improving microalgae cultivation.

\section{Countering the negative effects of stress via transcription factor engineering}

Transcription factors (TFs) are global regulators of biological pathways that act by up- or downregulating target genes, which have been widely used to construct robust microalgal strains (Table 2). Compared to directed modification of specific enzymes, TFs engineering can provide more substantial metabolic modification by controlling multiple steps in a pathway [82]. In fact, diverse "omics" technologies, including genomics, transcriptomics, lipidomics, proteomics, and metabolomics, are powerful tools to identify stress-response genetic targets under stress condition [83-85]. For example, using a combined omics (transcriptomic, proteomic and metabolomic) analysis, about 70 TFs genes were identified in $C$. reinhardtii that are involved in controlling nitrogen-deprivation process [86]. In recent years, an increasing number of TFs function have been confirmed by direct genetic experiments (Fig. 1).

Dof-type transcription factor was suggested to regulate the transcription of many genes involved in lipid biosynthesis via directly interacting with DNA in their promoter regions. Overexpression of a Dof-type TF (GmDof4) greatly increased lipid production of Arabidopsis, and authors found that the acetyl-coenzyme A carboxylase (ACCase) gene was up-regulated in transgenic plants [87]. ACCase is responsible for transforming acetyl-CoA into malonyl-CoA, which is the first and ratelimiting step for the biosynthesis of fatty acids. When overexpressed a Dof-type TF, the total lipid production of C. reinhardtii CC-137 was also increased by twofold [88]. In transgenic strain, the expression of the enoyl-ACPreductase (ENR1) and the sulfolipid synthase (SQD2) genes was greatly up-regulated, which is a key gene related to fatty acid synthase (FAS) and the glycerolipid biosynthesis, respectively [88]. Furthermore, Salas-Montantes et al. [89] investigated the feasibility for improving 
Table 2 Transcription factors involved in stresses

\begin{tabular}{|c|c|c|c|c|}
\hline Species & $\begin{array}{l}\text { Transcription } \\
\text { factors }\end{array}$ & Stresses & Performances & References \\
\hline Chlamydomonas reinhardtii & PHR1 & Phosphate starvation & $\begin{array}{l}\text { PHR1 acts downstream in the phosphate starvation signaling } \\
\text { pathway via binding the promoter of phosphate starvation } \\
\text { responsive structural genes }\end{array}$ & {$[83]$} \\
\hline Chlamydomonas reinhardtii & LCR1 & $\mathrm{CO}_{2}$-limiting stress & $\begin{array}{l}\mathrm{LCR} 1 \text { transmits the low } \mathrm{CO}_{2} \text { signal to at least three } \\
\mathrm{CO}_{2} \text {-responsive genes and then fully induces carbon-concen- } \\
\text { trating mechanism }\end{array}$ & {$[94]$} \\
\hline Dunaliella bardawil & WRKY & Salt stress & $\begin{array}{l}\text { All the carotenogenic genes can be recognized by WRKY tran- } \\
\text { scription factors }\end{array}$ & {$[95]$} \\
\hline Chlamydomonas & NRR1 & Nitrogen starvation & $\begin{array}{l}\text { NRR1, a putative SQUAMOSA promoter binding protein-type } \\
\text { transcription factor, was proved to be a regulator of } \mathrm{N} \text {-induced } \\
\text { TAG biosynthesis }\end{array}$ & {$[86]$} \\
\hline Chlamydomonas reinhardtii & PSR1 & Nitrogen starvation & PSR1 is a pivotal switch that triggers cytosolic lipid accumulation & {$[93]$} \\
\hline Chlamydomonas reinhardtii & PSR1 & Phosphorus starvation & $\begin{array}{l}\text { PSR1 gene is an important determinant of lipid and starch } \\
\text { accumulation in response to phosphorus starvation but not } \\
\text { nitrogen starvation }\end{array}$ & {$[92]$} \\
\hline Chlorella ellipsoidea & GmDof4 & Nitrogen starvation & Increase of lipid content without growth limitation & {$[90]$} \\
\hline Nannochloropsis salina & $\mathrm{NsbHLH} 2$ & Nitrogen limitation & $\begin{array}{l}\text { Biomass and FAME productivity was increased by } 36 \% \text { and } 33 \% \text {, } \\
\text { respectively }\end{array}$ & [99] \\
\hline Nannochloropsis gaditana & ZnCys & Nitrogen starvation & Lipid is doubled by attenuation of ZnCys expression & {$[100]$} \\
\hline
\end{tabular}

lipid accumulation of $C$. reinhardtii under nutrient deficiency stress by overexpression of a Dof-type TF (Dof11), and results showed that the lipid content and the proportion of specific fatty acids were all increased. Similarly, a combination of the overexpression of GmDof4 and mixotrophic culture condition was investigated in microalgae Chlorella ellipsoidea, and results showed that the lipid content was increased from 46.4 to $52.9 \%$ with no impact over the growth rate [90]. Furthermore, analysis results indicated that the expression of 754 genes was up-regulated and that of 322 genes was down-regulated in transgenic C. ellipsoidea, which suggested that GmDof4 may regulate genes related to fatty acid, lipid, carbohydrate metabolism, and protein [90].

A MYB-type transcription factors, Pi Starvation Response1 (PSR1), was found to regulate phosphate starvation signaling by up-regulating phosphatases and $\mathrm{Pi}$ transporters. Under P starvation, PSR1 mutation of $C$. reinhardtii not only inhibited lipid biosynthesis but also abolished starch production induced by starvation [91]. Furthermore, Bajhaiya et al. [92] examined the metabolic regulatory role of PSR1 under P starvation, and found that its overexpression increased starch biosynthesis of $C$. reinhardtii, which correlated with a higher expression of specific starch metabolism genes such as starch synthase (SSS1) and phosphorylases (SP1). In author study, PSR1 has also been identified as a regulator of TAG biosynthesis in response to nitrogen starvation in C. reinhardtii, and its overexpression increased TAG accumulation without inhibiting growth [93]. However, that study did not examine the expression level of downstream target genes and the potential mechanism of PSR1 under P starvation. Moreover, it was reported that MYB-type TF also play a role in $\mathrm{CO}_{2}$-responsive genes in $C$. reinhardtii and salt tolerance in Dunaliella bardawil, but lack confirmation by direct genetic experiments [94, 95].

A significant landmark was the identification of nitrogen response regulator NRR1 in Chlamydomonas. Insertional mutant NRR1 resulted in a reduction of TAG accumulation by $50 \%$, and its expression was unaffected by other nutrient deficiencies, indicating that this regulator was exclusive to nitrogen-deprivation condition [96]. However, the role of NRR1 in other oleaginous microalgae has not been recapitulated. An intriguing alternative approach to overcome growth limitation under nutrient starvation involves controlling cell quiescence. $\mathrm{CHT} 7$ is a transcription factor that regulates quiescence and proliferation under nutrient-starved and -replete conditions, and C. reinhardtii mutations of CHT7 can promote starvation-induced TAG accumulation without limiting the biomass yield [97]. Another study identified the regulator TAR1 that has pleiotropic function in response to nitrogen deficiency by regulating cell growth and photosynthesis repression [98]. Compared with the wild type, the TAR1-defective C. reinhardtii mutant exhibited more pronounced arrest of cell division, resulting in a $10 \%$ higher TAG yield [98]. In Nannochloropsis salina, overexpression of the transcription factor NsbHLH2 increased biomass productivity by $36 \%$ and FAME productivity by $33 \%$ under nitrogen-limitation stress [99]. As for 
knockout of TF, the lipid accumulation regulator $\mathrm{ZnCys}$ in Nannochloropsis gaditana was knockout by Cas9mediated insertional attenuation, and results showed that the lipid productivity was doubled without a concomitant growth limitation under nutrient-replete conditions [100]. However, the availability of these TFs needs to be further proven in more oleaginous microalgae.

Additionally, there is a chance of manipulating the stress-responsive promoters for the increased lipid accumulation. To improve lipid biosynthesis under P deprivation in C. reinhardtii, Iwai et al. [101] established an overexpression depending on $\mathrm{P}$ deprivation construct of a Chlamydomonas type-2 diacylglycerol acyl-CoA acyltransferase (DGTT4), where a P starvation-inducible promoter was introduced. Furthermore, the introduction of this heterologous promoter into Nannochloropsis sp. also enhanced the lipid accumulation under P starvation [102]. Taken together, transcription factor engineering is a promising methodology to be included in the microalgal biotechnology toolkit, but much additional research and development are necessary to further understand and validate the use of these tools, especially in relation to secondary metabolism.

\section{Adaptive laboratory evolution}

Microorganisms have the ability to adapt rapidly to changing environments. Under severe stress, adaptation can occur via acquisition of beneficial phenotypes by random genomic mutations and subsequent positive selection [103, 104]. It is, therefore, not surprising that this plasticity of microorganisms has been harnessed for improving growth under stress conditions [21]. In contrast to the directed modification of particular enzymes and the rational engineering strategies, ALE enjoys the advantage of making the non-intuitive beneficial mutations take place within various regulatory regions and genes in parallel [105]. Moreover, engineering microalgae strains for overproduction of carotenoids or lipids usually requires the extensive genetic modifications, which often result in a great reduction of cellular fitness. On the contrary, ALE allows the phenotypic changes to be obviously connected with specific growth environment that results in the selection of the traits, which can not only overcome such negative effect but also lead to improvements in the physiological fitness of the strains. ALE has been widely utilized to change phenotypic and biological functions of many model organisms, such as Escherichia coli and Saccharomyces cerevisiae [105-107].

\section{Choice of stress conditions and equipment}

During microbial ALE, a microorganism is cultivated under clearly defined conditions for prolonged periods of time, in the range of weeks to years, which allows the selection of improved phenotype. The selective stress serves as the first and also the foremost step for the success of ALE. It can be classified into two major categories, including the environmental stress and the nutrient stress [108]. In Chlorococcum littorale, ALE experiments were done using two different cycles: repeated long starvation (13 days of $N=0$ ) lasting for 75 days and also repeated short starvation ( 6 days of $N=0$ ) over a total period of 72 days. However, there was no difference shown in the production of biomass and lipid by the longer or shorter periods of starvation, suggesting that $C$. littorale might not fit the induction of the changes through ALE using nitrogen starvation as a stress factor [109]. If aiming to stimulate the growth performance of $C$. littorale, people should consider that ALE experiments are conducted under intensive selective pressure such as high light or high temperature. By contrast, ALE with nitrogen-starvation stress successfully improved the cell growth and lipid accumulation of $C$. reinhardtii [110], indicating the response to repeated stress is highly strain dependent. In this regard, one should pay attention to which stress condition can most potentially affect one's working strain.

Another important parameter that affects the outcome of ALE experiment is the passage size, which decides how much of the population is permitted to propagate to each subsequent batch culture. If there is a beneficial mutation but is lost due to the population size bottlenecks, then the evaluation rate would be halted or slowed. It has been shown from the evolution experiments that the mutator hitchhiking can be seriously delayed among the smaller population bottlenecks [111]. However, enhancing the passage size would enhance the possibility of realizing the beneficial mutation, but also lead to increase in the resources needed to sustain. Due to this, the passage size is often determined by an individual's schedule. For the microalgae, the impact of the passage size on the ALE experiment has not been systematic explored.

In addition to the choice of selection pressure, ALE methods depend on culture equipment. In general, it is relatively easy to establish the ALE experiments. The common approaches usually include serial transfer, colony transfer or chemostat culture (Fig. 3). Serial transfer from a liquid medium and colony transfer from a solid medium were used for the sequential transfer of cells in repetitive cultures [112]. Put simply, an aliquot of the culture is transferred to a new flask or culture dish with fresh medium for an additional round of growth at regular intervals. Clearly, these easy setups have the advantage of cheap equipment and ease of massive parallel culture. By contrast, the central principle of the chemostat is that a stable equilibrium is achieved through the continuous addition of medium and simultaneous removal of culture broth [113]. In this constant steady 


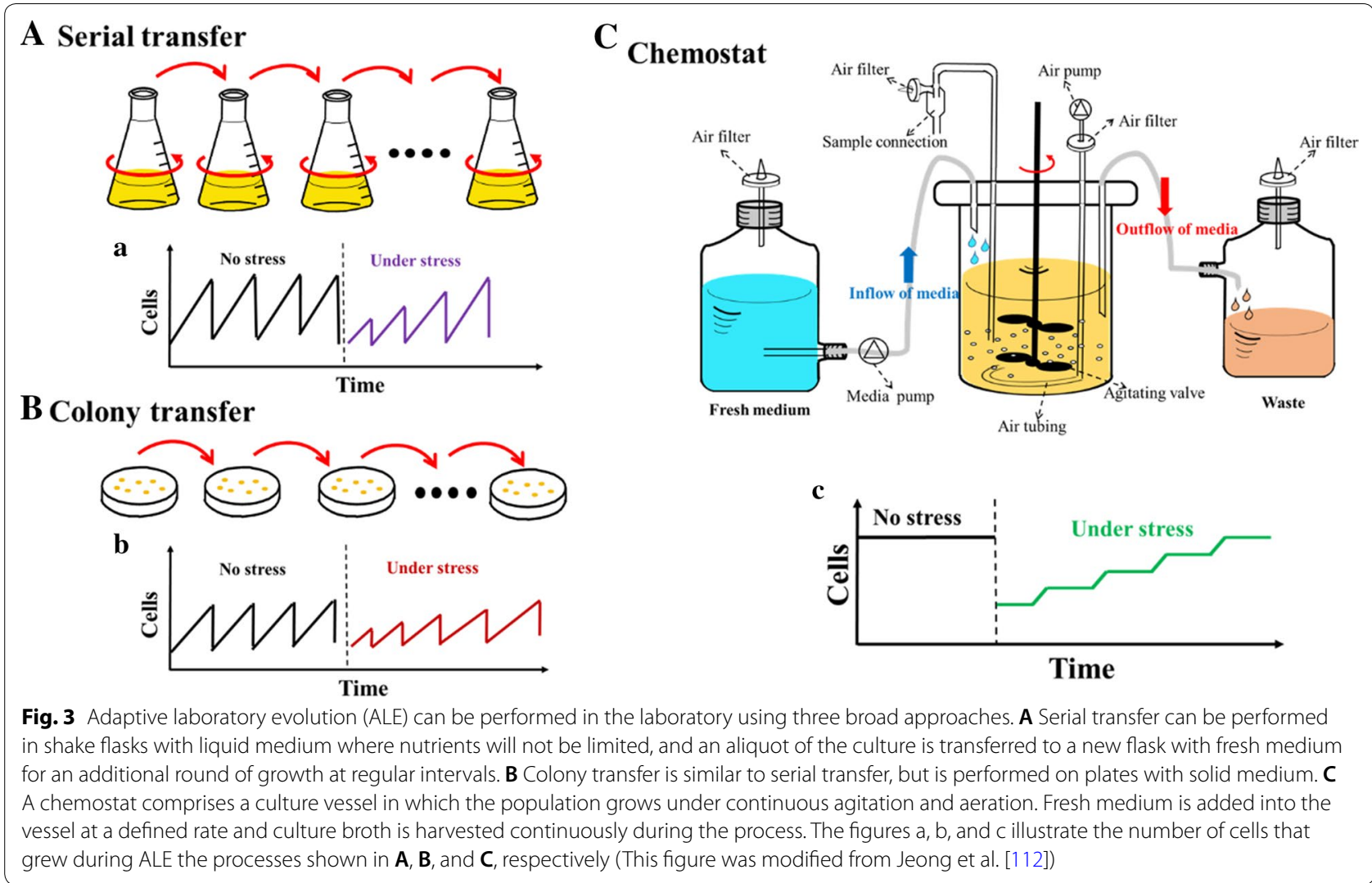

state, defined nutrient- and environmental stresses can be finely tuned, and the growth rate of the cells can be experimentally controlled by modulating the rate of culture dilution. Although chemostat culture requires complex procedures that come with a higher cost, the larger cell population of the chemostat provides more genetic diversity than the smaller population of transfer techniques. Moreover, continuous selection using the chemostat technique can result in shorter times of ALE, which in turn can reduce the overall project cost.

\section{Development of stress-tolerant strains by adaptive laboratory evolution}

In recent years, there were many ALE experiments being conducted successfully and applied to enhance the production of lipid or other high value-added products in microalgae (Table 3). Here, we summarized the most important workers regarding the ALE strategies with the aim of improving the stress tolerance of microalgae strains, as well as the production of lipid and carotenoids. The most common stress factors used for improving the performance of microalgae can also be divided into the categories of nutrient stress, environmental stress, oxidative stress, and natural selection stress.

\section{Nutrient stresses}

The efficiency of nutrient utilization is an important aspect of microbial growth, and for industrial purposes, it may be governed by factors such as substrate costs or increased bioconversion rates. Although previous studies demonstrated that glucose is comparatively better compared with other carbon sources in stimulating DHA accumulation in C. cohnii, high glucose concentrations remain inhibiting cell growth and lipid accumulation [114]. To stimulate the high cell growth and release the substrate inhibition, ALE was performed for 650 days with gradually enhanced glucose concentration. Compared to the parent strain, glucose-tolerant C. cohnii strain yielded $15.49 \%$ more lipid accumulation [115]. The following metabolomics analysis suggested that the increased glucose tolerance was mediated by a positive regulation of glycerol, glutamic acid, succinic acid, and malonic acid, and negative regulation of tyrosine, lyxose, and fructose [115].

In addition to glucose, glycerol, the cheap by-product of biodiesel production, is also a potentially attractive substrate for the production of high value-added materials by fermentation. However, an engineered strain of Rhodococcus opacus MITXM-61 did not produce TAG on glycerol and grew poorly. Subsequently, an adaptive 
Table 3 Typical adaptive laboratory evolution experiments with microalgae

\begin{tabular}{|c|c|c|c|c|}
\hline Microalgal species & Selection pressure & Selection time & Performance & References \\
\hline Chlamydomonas reinhardtii & Nitrogen limitation & 50 days & $\begin{array}{l}\text { The numbers of intracellular lipid bodies was mas- } \\
\text { sively increased }\end{array}$ & [110] \\
\hline Crypthecodinium cohnii & Inhibitory concentration of glucose & 650 days & High biomass and lipid accumulation was achieved & {$[115]$} \\
\hline Rhodococcus opacus & High glycerol concentration & 22 days & The conversion of glycerol into TAG was improved & {$[116]$} \\
\hline Rhodococcus opacus & Phenol as sole carbon source & 40 passages & The lipid production was increased by twofold & {$[117]$} \\
\hline Chlamydomonas reinhardtii & Nitrogen starvation & 84 days & Lipid productivity was increased by 2.36 times & {$[118]$} \\
\hline Chlorella vulgaris & $660 \mathrm{~nm}$ LEDs & 114 days & Maximum biomass density was achieved & {$[119]$} \\
\hline Dunaliella salina & Combined blue and red light & 80 days & $\begin{array}{l}\text { Increase of accumulation of carotenoids under com- } \\
\text { bined blue and red light }\end{array}$ & {$[110]$} \\
\hline Phaeodactylum tricornutum & Combined blue and red light & 60 days & $\begin{array}{l}\text { Increase of biomass production and fucoxanthin } \\
\text { accumulation }\end{array}$ & {$[122]$} \\
\hline Chlorella sp. & $10 \%$ and $20 \% \mathrm{CO}_{2}$ & 97 days & $\begin{array}{l}\text { Enhanced } \mathrm{CO}_{2} \text { fixation capability and carotenoids } \\
\text { accumulation }\end{array}$ & [123] \\
\hline Schizochytrium sp. & Agitation at 230 rpm & 40 days & $\begin{array}{l}\text { Maximum cell dry weight and DHA yield were } \\
\text { observed }\end{array}$ & {$[131]$} \\
\hline
\end{tabular}

evolution strategy was applied by gradually adding glycerol into glucose/xylose medium, and the conversion of glycerol into TAG was improved successfully [116]. However, the genetic constitution of evolved strain was not unidentified. Surprisingly, Yoneda et al. [117] adaptively evolved $R$. opacus over 40 passages using phenol as sole carbon source. The endpoint strains showed higher phenol consumption rates and twofold higher lipid production from phenol than the wild-type strain. Whole-genome sequencing and comparative transcriptomics identified highly upregulated genes such as phenol monooxygenase reductase and shikimate transporter gene, implying that increased phenol import is more important than export in phenol tolerance in $R$. opacus. Moreover, lipid biosynthesis genes, including fatty acid synthesis gene (FAS) and desaturase genes, were also greatly up-regulated in evolved strain, which is consistent with the increase of lipid production.

In a somewhat different approach, $C$. reinhardtii was subjected to nitrogen limitation stress over 50 days to enhance the lipid production. After adaptive evolution, wild-type strain CC124 and starch-less mutant cells showed a $50 \%$ and $175 \%$ increase, respectively [110]. Furthermore, proteomics analyses showed that the key control protein [periplasmic L-amino acid oxidase (LAO1)] of carbon-nitrogen integration was specifically overexpressed. Moreover, the enzymes involved in lipid metabolism and lipid body-associated proteins (glutathione-S-transferases and esterase), were also induced during adaptive evolution [110]. When C. reinhardtii was conducted ALE combined with nitrogenstarvation stress for 84 days, the lipid productivity was increased by 2.36 times [118].

\section{Environmental stresses}

Among environmental stresses, adaptation of microalgae to unfavorable light conditions was investigated in the largest number of studies. The biomass productivity of microalgae is a key limiting factor of economic feasibility, especially in photosynthetic processes. A process spanning 114 days of ALE was used to improve the biomass productivity and cell density of $C$. vulgaris grown under less expensive lighting by $660 \mathrm{~nm}$ LEDs instead of the traditional but more expensive 680-nm LEDs [119]. In addition, ALE with light stress was also linked to increased carotenoids production. For example, Fu et al. [120] applied ALE to obtain mutants of D. salina (HI 001) with grown carotenoids accumulation, including the lutein and $\beta$-carotene under the combined red-and bluelight stress. Wild-type $D$. salina strains are not suitable for industrial production of lutein since they are sensitive to red light and unable to grow fast at high light intensities. By contrast, the ALE-derived strain D. salina (HI 001) can withstand high light stress, and therefore holds promise as an industrial lutein producer. Subsequently, the authors selected light quality, osmotic stress and nitrate concentration as three representative stressors to again enhance the lutein production in D. salina (HI 001) [121]. Similarly, in the marine diatom Phaeodactylum tricornutum, ALE with combined red-and blue-light stress also led to the increase of biomass production and fucoxanthin accumulation [122].

Moreover, to enhance the $\mathrm{CO}_{2}$ fixation ability of Chlorella sp., ALE was proposed under $10 \% \mathrm{CO}_{2}$ condition to improve its $\mathrm{CO}_{2}$ tolerance, which led to increased accumulation of chlorophylls and carotenoids [123]. Nevertheless, this study did not investigate the physiological parameters and gene expression. Furthermore, a 
gradient-based adaptive evolution method was developed to increase the $\mathrm{CO}_{2}$ tolerance of $\mathrm{H}$. pluvialis using 15\% $\mathrm{CO}_{2}$ as selection stress. After 10 generations, the biomass and astaxanthin yields of the domesticated mutant in an atmosphere comprising $15 \% \mathrm{CO}_{2}$ were 1.3 times and 6 times higher than in normal air, which might be attributed to the up-regulation expression of photosynthetic enzymes such as ATP synthase and RuBisCO genes [124].

In most of the microalgae, high-salt stress is beneficial to lipid accumulation, but itusually led to the decrease of photosynthetic pigments and oxidative damage. To obtain salt stress-tolerant microalgae, 1255 generations of ALE towards high-salt stress $(200 \mathrm{mM} \mathrm{NaCl})$ were performed in the green alga $C$. reinhardtii, and then yielded strains could grow as rapidly in high salt medium as the progenitor strain under normal conditions. Upon nitrogen depletion, the evolved cells were able to accumulate comparable amounts of lipid to those of the progenitor strain [125], which accompanied with significant up-regulation of calmodulin protein and downregulation of glycerol/phospholipid acyltransferase and transporters. Similarly, this phenomenon was in agreement with an earlier study [126]. Recently, salt-resistant Chlamydomonas sp. strains were bred using a combined ALE and mutation strategy, which showed that the biomass production under high salinity was dramatically improved in the salt-resistant strains, but the lipid accumulation was decreased [127]. By contrast, when an ALE strategy combined with $30 \mathrm{~g} / \mathrm{L} \mathrm{NaCl}$ was applied in marine microalgae Schizochytrium sp., evolved strain exhibited a maximum biomass of $134.5 \mathrm{~g} / \mathrm{L}$ and lipid yield of $80.14 \mathrm{~g} / \mathrm{L}$, resulting a $32.7 \%$ and $53.31 \%$ increase over the parental strain, respectively [128]. Despite of several benefits, the main limitation of ALE strategy is that most of the results are microalgae specific and its outcome may be different from strain to strain.

\section{Oxidative stress}

Apart from light, temperature and salt stress, oxidative stress also plays a vital role in cell proliferation and lipid accumulation in microalgae. Polyunsaturated fatty acids (PUFAs) imbue the cells with strong oxidation resistance $[129,130]$, and a high-oxygen stimulus might, therefore, induce the cells to produce more PUFA to protect themselves from oxidative injury. Based on this, ALE under continuous high oxygen was successfully applied to enhance the DHA production of Schizochytrium sp. [131]. It has been reported that microalgae with higher tolerance to oxidative stress are better suited for biofuel production [132]. In this regard, our recent study developed an innovative ALE strategy composed by cooperative two factors on the basis of the concomitant high salinity and low temperature to generate a stable improved Schizochytrium sp. strain that efficiently produce the lipid rich in PUFA. In this strategy, high salinity was used to trigger the lipid accumulation and promote the anti-oxidative defense systems of Schizochytrium sp., and low-temperature stress aimed to improve the PUFA content [133].

\section{Natural selection stress}

Compared to intentional adaptive evolution, natural adaptive evolution of strains possesses a greater probability for the culture to maintain the desired traits, although it is less likely to obtain a strain with desired characteristics. Using this strategy, Shin et al. [134] isolated and characterized a novel derivative of $C$. reinhardtii, which accumulated $116 \%$ and $66 \%$ more lipid under nitrogen- and sulfur-depleted conditions, respectively, than the ancestral strain. After evolution for 1880 generations in liquid medium under continuous light, the final C. reinhardtii strain had a $35 \%$ greater growth rate than the progenitor population, which was beneficial for lipid production [135].

Notably, the increasing application of ALE during recent years can be attributed to the ease of the access and decreasing costs of genome sequencing. Decreasing sequencing costs have led to increased investigation of "omics" technologies over the course of evolution, facilitating the study of fundamental stressresponse mechanisms of microalgae. For example, an ALE approach was developed to evolve a strain of the microalga Synechocystis sp. with an improved growth performance under acid stress at $\mathrm{pH}$ 5.5. A subsequent whole-genome sequence analysis suggested that SNPs in certain genes are involved in acid stress tolerance [136]. Similarity, heat-tolerant strains of Synechocystis sp. were obtained by ALE, and the affected genes were identified by whole-genome sequencing [137]. Transcriptome analysis of salt-tolerant $C$. reinhardtii revealed gene expression differences between longterm and short-term acclimation [125]. Metabolomics and comparative transcriptomics have been used to elucidate the mechanism of butanol and phenol tolerance of evolved Synechocystis sp. and R. opacus, respectively $[117,138]$. Genome-scale tools can identify the stress-responsive genetic elements responsible for an evolved phenotype. Furthermore, for a comprehensive and in-depth application of ALE strategy, genetic engineering and synthetic biology approaches should be developed to reintroduce point- or combined mutations into the parental strains in order to determine their specific phenotypic consequences. 


\section{Challenges and future perspective}

Microalgae have received a great amount of attention as potential cell factories for the production of bioactive compounds such as fatty acids and carotenoids. To overcome the negative effect of stress-based strategies, two-stage cultivation processes and the external addition of phytohormones or antioxidants can solve the conflicts between the accumulation of biomass and target product yields. However, the majority of these reports was conducted on the basis of laboratory-scale investigations and only were proven in minority microalgae species. Largescale trials and economic feasibility studies of these strategies are still needed to verify their application. When moving from the lab production unit to a large scale, there are some relevant variables including large-scale photobioreactor, carbon dioxide availability, energy supply, as well as nutrient availability. Before, the behavior of photobioreactor has been discussed by Singh et al. [139], but they did not provide final direction. Therefore, above variables should be considered in the large-scale trials of these strategies.

ALE has become a proven powerful tool for the development robust stress-tolerant strains for improved production of lipid and carotenoids. However, there are no standardized procedures available for designing and performing ALE experiments. With the availability of computer simulations and automation, it is time to build new evolutionary model that simulates the dynamics of ALE experiment. Not only that, there are other problems hindering the development of ALE, such as the gene instability of evolved strain, longer operation time, and lower mutation rate evolution. To prevent degradation of strain performance, single colonies selected after ALE should be strictly performed. Periodical adaptive evolution is also a choice to strengthen gene stability of evolved strain. In the further, genetic engineering could be applied to regulate enzymes that involved in maintaining a high fidelity of DNA replication and repair, then the mutation rates in ALE process could be increased.

While a large number of studies focused on improving growth, only few studies were devoted to alleviate oxidative stress. Therefore, obtaining optimized microalgal strains with strong antioxidant potential is the key factor for stable and sustainable cultivation of microalgae, which is extremely important for industrial applications. In this regard, ALE could be applied to increase the oxidative stress tolerance of microalgae. Moreover, genetic engineering efforts need to be directed towards enhancing the antioxidant systems of microalgae. This can be done by overexpressing antioxidant enzymes and expressing stress tolerance genes from other organisms. In a recent study, overexpression of SOD in microalgae Schizochytrium sp. successfully alleviated oxidative stress and increased the lipid content [140]. It is anticipated that the dramatic progress of innovative technologies will offer more chances for unraveling the regulatory networks responsible for the cellular reactions to oxidative stress, which might offer guidance for the improved microbial lipid and carotenoids overproduction.

\begin{abstract}
Abbreviations
ABA: abscisic acid; ALE: adaptive laboratory evolution; APX: ascorbate peroxidase; CAT: catalase; DAH: diethyl aminoethyl hexanoate; DHA: docosahexaenoic acid; EPA: eicosapentaenoic acid; GSH: glutathione; IAA: indole-3-acetic acid; PUFA: polyunsaturated fatty acids; ROS: reactive oxygen species; SOD: superoxide dismutase; TAG: triacylglycerol.
\end{abstract}

\section{Author contributions}

XMS and LJR conceived the idea and wrote the first draft of the manuscript. SXM and ZQY designed the figures. JXJ drafted the table. LJR and HH contributed to manuscript revision and approved the final version. All authors read and approved the final manuscript.

\section{Author details \\ ${ }^{1}$ College of Biotechnology and Pharmaceutical Engineering, Nanjing Tech University, No. 30 South Puzhu Road, Nanjing 211816, People's Republic of China. ${ }^{2}$ School of Pharmaceutical Sciences, Nanjing Tech University, No. 30 South Puzhu Road, Nanjing 211816 , People's Republic of China. ${ }^{3}$ State Key Laboratory of Materials-Oriented Chemical Engineering, Nanjing Tech University, No. 5 Xinmofan Road, Nanjing 210009, People's Republic of China. \\ ${ }^{4}$ Jiangsu National Synergetic Innovation Center for Advanced Materials (SICAM), Nanjing, People's Republic of China.}

\section{Acknowledgements}

This work was financially supported by the Outstanding Youth Foundation of Jiangsu Nature Science Foundation (BK20160092), the Program for Innovative Research Team in University of Jiangsu Province (2015) and the support of Jiangsu Synergetic Innovation Center for Advanced Bio-Manufacture (XTE1829, XTC1810)

\section{Competing interests}

The authors declare that they have no competing interests.

Consent for publication

The authors have consented for publication.

Ethics approval and consent to participate

Not applicable.

\section{Publisher's Note}

Springer Nature remains neutral with regard to jurisdictional claims in published maps and institutional affiliations.

Received: 14 June 2018 Accepted: 26 September 2018

Published online: 04 October 2018

\footnotetext{
References

1. Skjånes K, Rebours C, Lindblad P. Potential for green microalgae to produce hydrogen, pharmaceuticals and other high value products in a combined process. Crit Rev Biotechnol. 2013;33:172-215.

2. Banerjee A, Kumar N, Varjani SJ, Guria C, Bandopadhyay R, Shukla P, Banerjee C. Computational modelling and prediction of microalgae growth focused towards improved lipid production. Singapore: Springer; 2018. p. 223-32.

3. Chojnacka K, Noworyta A. Evaluation of Spirulina sp. growth in photoautotrophic, heterotrophic and mixotrophic cultures. Enzyme Microb Technol. 2004;34:461-5
} 
4. Perez-Garcia O, Escalante FME, De-Bashan LE, Bashan Y. Heterotrophic cultures of microalgae: metabolism and potential products. Water Res. 2011:45:11-36.

5. Chisti Y. Biodiesel from microalgae. Biotechnol Adv. 2007;25:294-306.

6. Saini DK, Pabbi S, Shukla P. Cyanobacterial pigments: perspectives and biotechnological approaches. Food Chem Toxicol. 2018;120:616-24.

7. Vershinin A. Biological functions of carotenoids-diversity and evolution. Comp Biochem Physiol A Mol Integr Physiol. 1999;124:99-104.

8. Chen CY, Kao AL, Tsai ZC, Shen YM, Kao PH, Ng IS, Chang JS. Expression of synthetic phytoene synthase gene to enhance $\beta$-carotene production in Scenedesmus sp. CPC2. Biotechnol J. 2017;12:1700268.

9. Yuan JP, Peng J, Yin K, Wang J-H. Potential health-promoting effects of astaxanthin: a high-value carotenoid mostly from microalgae. Mol Nutr Food Res. 2011;55:150-65.

10. Chisti Y. Constraints to commercialization of algal fuels. J Biotechnol. 2013;167:201-14

11. Gong M, Bassi A. Carotenoids from microalgae: a review of recent developments. Biotechnol Adv. 2016;34:1396-412.

12. Singh P, Kumari S, Guldhe A, Misra R, Rawat I, Bux F. Trends and novel strategies for enhancing lipid accumulation and quality in microalgae. Renew Sustain Energy Rev. 2016:55:1-16.

13. Duan X. Salt-induced osmotic stress for lipid overproduction in batch culture of Chlorella vulgaris. Afr J Biotechnol. 2012;11:7072-8.

14. Takagi M, Karseno, Yoshida T. Effect of salt concentration on intracellular accumulation of lipids and triacylglyceride in marine microalgae Dunaliella cells. J Biosci Bioeng. 2006;101:223-6.

15. Coesel SN, Baumgartner AC, Teles LM, Ramos AA, Henriques NM, Cancela L, Varela JCS. Nutrient limitation is the main regulatory factor for carotenoid accumulation and for Psy and Pds steady state transcript levels in Dunaliella salina (Chlorophyta) exposed to high light and salt stress. Mar Biotechnol. 2008;10:602-11.

16. Lu Y, Jian X. Phytohormones in microalgae: a new opportunity for microalgal biotechnology? Trends Plant Sci. 2015;20:273-82.

17. Ren LJ, Sun XM, Ji XJ, Chen SL, Guo DS, Huang H. Enhancement of docosahexaenoic acid synthesis by manipulation of antioxidant capacity and prevention of oxidative damage in Schizochytrium sp. Bioresour Technol. 2016;223:141-8.

18. Anila N, Simon DP, Chandrashekar A, Ravishankar GA, Sarada R. Metabolic engineering of Dunaliella salina for production of ketocarotenoids. Photosynth Res. 2016;127:321-3.

19. Ng IS, Tan SI, Kao PH, Chang YK, Chang JS. Recent developments on genetic engineering of microalgae for biofuels and bio-based chemicals. Biotechnol J. 2017;12:1700015.

20. Kao PH, Ng IS. CRISPRi mediated phosphoenolpyruvate carboxylase regulation to enhance the production of lipid in Chlamydomonas reinhardtii. Bioresour Technol. 2017;245:1527-37.

21. Lu L, Wei L, Zhu K, Wei D, Hua Q. Combining metabolic engineering and adaptive evolution to enhance the production of dihydroxyacetone from glycerol by Gluconobacter oxydans in a low-cost way. Bioresour Technol. 2012;117:317-24

22. Wang D, Ju X, Zhou D, Wei G. Efficient production of pullulan using rice hull hydrolysate by adaptive laboratory evolution of Aureobasidium pullulans. Bioresour Technol. 2014;164:12-9.

23. Jagadevan S, Banerjee A, Banerjee C, Guria C, Tiwari R, Baweja M, Shukla $P$. Recent developments in synthetic biology and metabolic engineering in microalgae towards biofuel production. Biotechnol Biofuels. 2018;11:185.

24. Banerjee A, Banerjee C, Negi S, Chang JS, Shukla P. Improvements in algal lipid production: a systems biology and gene editing approach. Crit Rev Biotechnol. 2017;38:369-85.

25. Banerjee C, Singh PK, Shukla P. Microalgal bioengineering for sustainable energy development: recent transgenesis and metabolic engineering strategies. Biotechnol J. 2016;11:303-14.

26. Illman AM, Scragg AH, Shales SW. Increase in Chlorella strains calorific values when grown in low nitrogen medium. Enzyme Microb Technol. 2000;27:631-5.

27. Khotimchenko SV, Yakovleva IM. Lipid composition of the red alga Tichocarpus crinitus exposed to different levels of photon irradiance. Phytochemistry. 2005;66:73-9.

28. Renaud SM, Thinh LV, Lambrinidis G, Parry DL. Effect of temperature on growth, chemical composition and fatty acid composition of tropical Australian microalgae grown in batch cultures. Aquaculture 2002;211:195-214.

29. Wensel P, Helms G, Hiscox B, Davis WC, Kirchhoff H, Bule M, Yu L, Chen S Isolation, characterization, and validation of oleaginous, multi-trophic, and haloalkaline-tolerant microalgae for two-stage cultivation. Algal Res. 2014;4:2-11.

30. Liu ZY, Wang GC, Zhou BC. Effect of iron on growth and lipid accumulation in Chlorella vulgaris. Bioresour Technol. 2008;99:4717-22.

31. Ra CH, Kang CH, Jung JH, Jeong GT, Kim SK. Effects of light-emitting diodes (LEDs) on the accumulation of lipid content using a twophase culture process with three microalgae. Bioresour Technol. 2016;212:254-61.

32. Ra CH, Kang CH, Na KK, Lee CG, Kim SK. Cultivation of four microalgae for biomass and oil production using a two-stage culture strategy with salt stress. Renew Energy. 2015;80:117-22.

33. Su CH, Chien LJ, Gomes J, Lin YS, Yu YK, Liou JS, Syu RJ. Factors affecting lipid accumulation by Nannochloropsis oculata in a two-stage cultivation process. J Appl Phycol. 2011;23:903-8.

34. Xie Y, Ho SH, Chen CN, Chen CY, Ng IS, Jing KJ, Chang JS, Lu Y. Phototrophic cultivation of a thermo-tolerant Desmodesmus sp. for lutein production: effects of nitrate concentration, light intensity and fed-batch operation. Bioresour Technol. 2013;144:435-44.

35. Lamers PP, Van de Laak CC, Kaasenbrood PS, Lorier J, Janssen M, De Vos RC, Bino RJ, Wijffels RH. Carotenoid and fatty acid metabolism in lightstressed Dunaliella salina. Biotechnol Bioeng. 2010;106:638-48.

36. Aflalo C, Meshulam Y, Zarka A, Boussiba S. On the relative efficiency of two- vs. one-stage production of astaxanthin by the green alga Haematococcus pluvialis. Biotechnol Bioeng. 2007;98:300-5.

37. Fábregas J, Otero A, Maseda A, Domínguez A. Two-stage cultures for the production of astaxanthin from Haematococcus pluvialis. J Biotechnol. 2001:89:65-71.

38. Park JC, Choi SP, Hong ME, Sim SJ. Enhanced astaxanthin production from microalga, Haematococcus pluvialis by two-stage perfusion culture with stepwise light irradiation. Bioprocess Biosyst Eng. 2014;37:2039-47.

39. Ho SH, Xie Y, Chan MC, Liu CC, Chen CY, Lee DJ, Huang CC, Chang JS. Effects of nitrogen source availability and bioreactor operating strategies on lutein production with Scenedesmus obliquus FSP-3. Bioresour Technol. 2015:184:131-8.

40. Sun H, Liu B, Lu X, Cheng KW, Chen F. Staged cultivation enhances biomass accumulation in the green growth phase of Haematococcus pluvialis. Bioresour Technol. 2017;233:326-31.

41. Wan M, Zhang J, Hou D, Fan J, Li Y, Huang J, Wang J. The effect of temperature on cell growth and astaxanthin accumulation of Haematococcus pluvialis during a light-dark cyclic cultivation. Bioresour Technol. 2014;167:276-83.

42. Fan JH, Huang JK, Li YG, Han FF, Wang J, Li XW, Li S. Sequential heterotrophy-dilution-photoinduction cultivation for efficient microalgal biomass and lipid production. Bioresour Technol. 2012;112:206-11.

43. Li Y, Hua X, Han F, Mu J, Di C, Bo F, Zeng H. Regulation of lipid metabolism in the green microalga Chlorella protothecoides by heterotrophyphotoinduction cultivation regime. Bioresour Technol. 2015;192:781-91.

44. Wan M, Zhang Z, Wang J, Huang J, Fan J, Yu A, Wang W, Li Y. Sequential heterotrophy-dilution-photoinduction cultivation of Haematococcus pluvialis for efficient production of astaxanthin. Bioresour Technol. 2015;198:557-63.

45. Flórez-Miranda L, Cañizares-Villanueva RO, Melchy-Antonio O, MartínezJerónimo F, Flores-Ortíz CM. Two stage heterotrophy/photoinduction culture of Scenedesmus incrassatulus: potential for lutein production. J Biotechnol. 2017;262:67-74.

46. Del RE, Acién FG, García-Malea MC, Rivas J, Molina-Grima E, Guerrero MG. Efficiency assessment of the one-step production of astaxanthin by the microalga Haematococcus pluvialis. Biotechnol Bioeng. 2010;100:397-402.

47. Pozo JCD, Lopez-Matas MA, Ramirez-Parra E, Gutierrez C. Hormonal control of the plant cell cycle. Physiol Plant. 2010;123:173-83.

48. Els S, Kabra AN, Ji MK, Kim JR, Min B, Jeon BH. Enhancement of microalgae growth and fatty acid content under the influence of phytohormones. Bioresour Technol. 2014;172:97-103.

49. Piotrowska-Niczyporuk A, Bajguz A. The effect of natural and synthetic auxins on the growth, metabolite content and antioxidant response of 
green alga Chlorella vulgaris (Trebouxiophyceae). Plant Growth Regul. 2014;73:57-66.

50. Liu J, Qiu W, Song Y. Stimulatory effect of auxins on the growth and lipid productivity of Chlorella pyrenoidosa and Scenedesmus quadricauda. Algal Res. 2016;18:273-80.

51. Liu J, Qiu W, Song Y, Peng H, Zhao Y. The growth and lipid productivity of Chlorella pyrenoidosa enhanced by plant hormones under ammonium stress. Environ Prog Sustain Energy. 2017;36:1187-93.

52. Babu AG, Wu X, Kabra AN, Kim DP. Cultivation of an indigenous Chlorella sorokiniana with phytohormones for biomass and lipid production under N-limitation. Algal Res. 2017;23:178-85.

53. Liu T, Liu F, Wang C, Wang Z, Li Y. The boosted biomass and lipid accumulation in Chlorella vulgaris by supplementation of synthetic phytohormone analogs. Bioresour Technol. 2017;232:44-52.

54. Park WK, Yoo G, Moon M, Kim CW, Choi YE, Yang JW. Phytohormone supplementation significantly increases growth of Chlamydomonas reinhardtii cultivated for biodiesel production. Appl Biochem Biotechnol. 2013;171:1128-42.

55. Trinh CT, Tran TH, Bui TV. Effects of plant growth regulators on the growth and lipid accumulation of Nannochloropsis oculata (droop) Hibberd. In: AIP conference proceedings; No. 1, 020017; AIP Publishing: Melville, NY, USA. 2017;1878

56. Sulochana SB, Arumugam M. Influence of abscisic acid on growth, biomass and lipid yield of Scenedesmus quadricauda under nitrogen starved condition. Bioresour Technol. 2016;213:198-203.

57. Tominaga $\mathrm{N}$, Takahata $\mathrm{M}$, Tominaga $\mathrm{H}$. Effects of $\mathrm{NaCl}$ and $\mathrm{KNO}_{3}$ concentrations on the abscisic acid content of Dunaliella sp. (Chlorophyta). Hydrobiologia. 1993;267:163-8.

58. Yoshida K, Igarashi E, Wakatsuki E, Miyamoto K, Hirata K. Mitigation of osmotic and salt stresses by abscisic acid through reduction of stressderived oxidative damage in Chlamydomonas reinhardtii. Plant Sci. 2004;167:1335-41.

59. Lu YD, Peng J, Liu SF, Gan QH, Cui HL, Song Q. Methyl jasmonate- or gibberellins a3-induced astaxanthin accumulation is associated with upregulation of transcription of $\beta$-carotene ketolase genes (bkts) in microalga Haematococcus pluvialis. Bioresour Technol. 2010;101:6468-74.

60. Gao Z, Meng C, Zhang X, Xu D, Miao X, Wang Y, Yang L, Lv H, Chen L, Ye $\mathrm{N}$. Induction of salicylic acid (sa) on transcriptional expression of eight carotenoid genes and astaxanthin accumulation in Haematococcus pluvialis. Enzyme Microb Technol. 2012:51:225-30.

61. Gao Z, Meng C, Zhang X, Xu D, Zhao Y, Wang Y, Lv H, Yang L, Chen L, Ye N. Differential expression of carotenogenic genes, associated changes on astaxanthin production and photosynthesis features induced by JA in H. pluvialis. PLoS ONE. 2012;7:e42243.

62. Zhao Y, Shang M, Xu JW, Zhao P, Li T, Yu X. Enhanced astaxanthin production from a novel strain of Haematococcus pluvialis using fulvic acid. Process Biochem. 2015;50:2072-7.

63. Lushchak VI. Adaptive response to oxidative stress: bacteria, fungi, plants and animals. Comp Biochem Physiol C Toxicol Pharmacol. 2011;153:175-90.

64. Imlay JA. Cellular defenses against superoxide and hydrogen peroxide. Annu Rev Biochem. 2008;77:755-76.

65. Montibus M, Pinson-Gadais L, Richard-Forget F, Barreau C, Ponts N. Coupling of transcriptional response to oxidative stress and secondary metabolism regulation in filamentous fungi. Crit Rev Microbiol. 2013:41:295-308.

66. Han XF, Zeng H, Bartocci P, Fantozzi F, Yan YJ. Phytohormones and effects on growth and metabolites of microalgae: a review. Fermentation. 2018;4:25.

67. Yoshida K, Igarashi E, Mukai M, Hirata K, Miyamoto K. Induction of tolerance to oxidative stress in the green alga, Chlamydomonas reinhardtii, by abscisic acid. Plant Cell Environ. 2003;26:451-7.

68. Chokshi K, Pancha I, Ghosh A, Mishra S. Nitrogen starvation-induced cellular crosstalk of Ros-scavenging antioxidants and phytohormone enhanced the biofuel potential of green microalga Acutodesmus dimorphus. Biotechnol Biofuels. 2017;10:60

69. Wu S, Meng Y, Cao X, Xue S. Regulatory mechanisms of oxidative species and phytohormones in marine microalgae Isochrysis zhangjiangensis under nitrogen deficiency. Algal Res. 2016;17:321-9.

70. Lu Y, Tarkowská D, Turečková V, Luo T, Xin Y, Li J, Wang Q, Jiao N, Strnad $\mathrm{M}, \mathrm{Xu}$ J. Antagonistic roles of abscisic acid and cytokinin during response to nitrogen depletion in oleaginous microalga Nannochloropsis oceanica expand the evolutionary breadth of phytohormone function. Plant J. 2014;80:52-68.

71. Hirt H. Connecting oxidative stress, auxin, and cell cycle regulation through a plant mitogen-activated protein kinase pathway. Proc Natl Acad Sci USA. 2000;97:2405-7.

72. Kovtun Y, Chiu W, Tena G, Sheen J. Functional analysis of oxidative stress-activated mitogen-activated protein kinase cascade in plants. Proc Natl Acad Sci USA. 2000:97:2940-5.

73. Khasin M, Cahoon RE, Alvarez S, Beckeris RG, Eyun SI, Jia Q, Riethoven $\mathrm{JJ}$, Nickerson KW, Riekhof WR. Synthesis, secretion, and perception of abscisic acid regulates stress responses in Chlorella sorokiniana. bioRxiv. 2017. https://doi.org/10.1101/180547.

74. Liu B, Liu J, Sun P, Ma X, Jiang Y, Chen F. Sesamol enhances cell growth and the biosynthesis and accumulation of docosahexaenoic acid in the microalga Crypthecodinium cohnii. J Agric Food Chem. 2015;63:5640-5.

75. Gaffney M, O'Rourke R, Murphy R. Manipulation of fatty acid and antioxidant profiles of the microalgae Schizochytrium sp. through flaxseed oil supplementation. Algal Res. 2014;6:195-200.

76. Singh D, Mathur AS, Tuli DK, Puri M, Barrow CJ. Propyl gallate and butylated hydroxytoluene influence the accumulation of saturated fatty acids, omega-3 fatty acid and carotenoids in thraustochytrids. J Funct Foods. 2015;15:186-92.

77. Kouzuma A, Watanabe K. Exploring the potential of algae/bacteria interactions. Curr Opin Biotechnol. 2015;33:125-9.

78. Do Nascimento M, Dublan ML, Ortiz-Marquez JC, Curatti L. High lipid productivity of an Ankistrodesmus-Rhizobium artificial consortium. Bioresour Technol. 2013;146:400-7.

79. De-Bashan LE, Antoun H, Bashan Y. Involvement of indole-3-acetic acid produced by the growth-promoting bacterium Azospirillum, spp. in promoting growth of Chlorella vulgaris. J Phycol. 2010;44:938-47.

80. Choix FJ, Debashan LE, Bashan Y. Enhanced accumulation of starch and total carbohydrates in alginate-immobilized Chlorella spp. induced by Azospirillum brasilense: I. Autotrophic conditions. Enzyme Microb Technol. 2012;51:300-9.

81. Nugroho WA, Nurlaili FR, Hendrawan Y, Argo BD. Effect of growth promoting bacteria on the growth rate and lipid content of microalgae Chorella sp. in sludge liquor of anaerobic digester of dairy manure. Int J Adv Sci Eng Inf Technol. 2015;5:374-8.

82. Chen X, Hu G, Liu L. Hacking an algal transcription factor for lipid biosynthesis. Trends Plant Sci. 2018;23:181-4.

83. Rubio V, Linhares F, Solano R, Martín AC, Iglesias J, Leyva A, Pazares J. A conserved MYB transcription factor involved in phosphate starvation signaling both in vascular plants and in unicellular algae. Gene Dev. 2001;15:2122-33

84. Ma Z, Tian M, Tan Y, Cui G, Feng Y, Cui Q, Song X. Response mechanism of the docosahexaenoic acid producer Aurantiochytrium under cold stress. Algal Res. 2017;25:191-9.

85. Gwak Y, Hwang YS, Wang B, Kim M, Jeong J, Lee CG, Hu Q, Han D, Jin E. Comparative analyses of lipidomes and transcriptomes reveal a concerted action of multiple defensive systems against photooxidative stress in Haematococcus pluvialis. J Exp Bot. 2014;65:4317-34.

86. Gargouri M, Park JJ, Holquin OF, Kim JM, Wang H, Deshpande RR, Hill YS, Hicks LM, Gang DR. Identification of regulatory network hubs that control lipid metabolism in Chlamydomonas reinhardtii. J Exp Bot. 2015;66:4551-66.

87. Wang HW, Zhang B, Hao YJ, Huang J, Tian AG, Liao Y, Zhang JS, Chen SY. The soybean Dof-type transcription factor genes, GmDof4 and GmDof11, enhance lipid content in the seeds of transgenic Arabidopsis plants. Plant J. 2010;52:716-29.

88. Ibáñezsalazar A, Rosalesmendoza S, Rochauribe A, Ramírezalonso Jl, Larahernández I, Hernándeztorres A, Pazmaldonado LM, Silvaramírez AS, Bañueloshernández B, Martínezsalgado JL. Over-expression of Doftype transcription factor increases lipid production in Chlamydomonas reinhardtii. J Biotechnol. 2014;184:27-38.

89. Salas-Montantes CJ, González-Ortega O, Ochoa-Alfaro AE, CamarenaRangel R, Paz-Maldonado LMT, Rosales-Mendoza S, Rocha-Uribe A, Soria-Guerra RE. Lipid accumulation during nitrogen and sulfur starvation in Chlamydomonas reinhardtii overexpressing a transcription factor. J Appl Phycol. 2018. https://doi.org/10.1007/s10811-018-1393-6. 
90. Zhang J, Hao Q, Bai L, Xu J, Yin W, Song L, Xu L, Guo X, Fan C, Chen $Y$, Ruan J, Hao S, Li Y, Wang RR, Hu Z. Overexpression of the soybean transcription factor $\mathrm{GmDof} 4$ significantly enhances the lipid content of Chlorella ellipsoidea. Biotechnol Biofuels. 2014;7:128.

91. Bajhaiya AK, Dean AP, Driver T, Trivedi DK, Rattray NJW, Allwood JW, Goodacre R, Pittman JK. High-throughput metabolic screening of microalgae genetic variation in response to nutrient limitation. Metabolomics. 2016;12:9.

92. Bajhaiya AK, Dean AP, Zeef LA, Webster RE, Pittman JK. PSR1 is a global transcriptional regulator of phosphorus deficiency responses and carbon storage metabolism in Chlamydomonas reinhardtii. Plant Physiol. 2015;170:1216-34.

93. Ngan $\mathrm{CY}$, Wong $\mathrm{CH}$, Choi $\mathrm{C}$, Yoshinaga $\mathrm{Y}$, Louie $\mathrm{K}$, Jia J, Chen $\mathrm{C}$, Bowen B, Cheng H, Leonelli L, Kuo R, Baran R, García-Cerdán JG, Pratap A, Wang M, Lim J, Tice H, Daum C, Xu J, Northen T, Visel A, Bristow J, Niyogi KK, Wei CL. Lineage-specific chromatin signatures reveal a regulator of lipid metabolism in microalgae. Nat Plants. 2015;1:15107.

94. Yoshioka S, Taniguchi F, Miura K, Inoue T, Yamano T, Fukuzawa H. The novel myb transcription factor Icr1 regulates the co2-responsive gene cah1, encoding a periplasmic carbonic anhydrase in Chlamydomonas reinhardtii. Plant Cell. 2004;16:1466-77.

95. Liang MH, Jiang JG. Analysis of carotenogenic genes promoters and wrky transcription factors in response to salt stress in Dunaliella bardawil. Sci Rep. 2017;7:37025

96. Boyle NR, Page MD, Liu B, Blaby IK, Casero D, Kropat J, Cokus SJ, Hong-Hermesdorf A, Shaw J, Karpowicz SJ, Gallaher SD, Johnson S, Benning C, Pellegrini M, Grossman A, Merchant SS. Three acyltransferases and nitrogen-responsive regulator are implicated in nitrogen starvation-induced triacylglycerol accumulation in Chlamydomonas. J Biol Chem. 2012;287:15811-25.

97. Tasi $\mathrm{CH}$, Warakanont J, Takeuchi T, Sears BB, Moellering ER, Benning C. The protein compromised hydrolysis of triacylglycerols 7 (CHT7) acts as a repressor of cellular quiescence in chlamydomonas. Proc Natl Acad Sci USA. 2014;111:15833-8.

98. Kajikawa M, Sawaragi Y, Shinkawa H, Yamano T, Ando A, Kato M, Hirono M, Sato N, Fukuzawa H. Algal dual-specificity tyrosine phosphorylation-regulated kinase, triacylglycerol accumulation regulator 1 , regulates accumulation of triacylglycerol in nitrogen or sulfur deficiency. Plant Physiol. 2015;168:752-64.

99. Kang NK, Jeon S, Kwon S, Koh HG, Shin SE, Lee B, Choi GG, Yang JW, Jeong BR, Chang YK. Effects of overexpression of a bHLH transcription factor on biomass and lipid production in Nannochloropsis salina. Biotechnol Biofuels. 2015;8:1-13.

100. Ajjawi I, Verruto J, Aqui M, Soriaga LB, Coppersmith J, Kwok K, Peach L, Orchard E, Kalb R, Xu W, Carlson TJ, Francis K, Konigsfeld K, Bartalis J, Schultz A, Lambert W, Schwartz AS, Brown R, Moellering ER. Lipid production in Nannochloropsis gaditana is doubled by decreasing expression of a single transcriptional regulator. Nat Biotechnol. 2017;35:647-52.

101. Iwai M, Ikeda K, Shimojima M, Ohta H. Enhancement of extraplastidic oil synthesis in Chlamydomonas reinhardtii using a type-2 diacylglycerol acyltransferase with a phosphorus starvation-inducible promoter. Plant Biotechnol J. 2014;12:808-19.

102. Masako I, Koichi H, Yuko SS, Mie S, Hiroyuki O. Manipulation of oil synthesis in Nannochloropsis strain NIES-2145 with a phosphorus starvation-inducible promoter from Chlamydomonas reinhardtii. Front Microbiol. 2015;6:912.

103. Rando OJ, Verstrepen KJ. Timescales of genetic and epigenetic inheritance. Cell. 2007;128:655-68.

104. Kim HJ, Jeong H, Hwang S, Lee MS, Lee YJ, Lee DW, Lee SJ. Short-term differential adaptation to anaerobic stress via genomic mutations by Escherichia coli strains k-12 and B lacking alcohol dehydrogenase. Front Microbiol. 2014;5:476.

105. Dragosits M, Mattanovich Dethard. Adaptive laboratory evolutionprinciples and applications for biotechnology. Microb Cell Fact. 2013:12:64-81.

106. Applebee MK, Joyce AR, Conrad TM, Pettigrew DW, Palsson BØ. Functional and metabolic effects of adaptive glycerol kinase (GLPK) mutants in Escherichia coli. J Biol Chem. 2011;286:23150-9.
107. Lee DH, Feist AM, Barrett CL, Palsson BØ. Cumulative number of cell divisions as a meaningful timescale for adaptive laboratory evolution of Escherichia coli. PLoS ONE. 2011;6:e26172.

108. Nam H, Conrad TM, Lewis NE. The role of cellular objectives and selective pressures in metabolic pathway evolution. Curr Opin Biotechnol. 2011;22:595-600.

109. Cabanelas ITD, Kleinegris DMM, Wijffels RH, Barbosa MJ. Repeated nitrogen starvation doesn't affect lipid productivity of Chlorococcum littorale. Bioresour Technol. 2016;219:576-82.

110. Velmurugan N, Sung M, Yim SS, Min SP, Ji WY, Jeong KJ. Systematically programmed adaptive evolution reveals potential role of carbon and nitrogen pathways during lipid accumulation in Chlamydomonas reinhardtii. Biotechnol Biofuels. 2014:7:1-15.

111. Raynes Y, Halstead AL, Sniegowski PD. The effect of population bottlenecks on mutation rate evolution in asexual populations. J Evol Biol. 2014;27:161-9.

112. Jeong H, Lee SJ, Kim P. Procedure for adaptive laboratory evolution of microorganisms using a chemostat. J Vis Exp. 2016;15:e54446.

113. Narang A. The steady states of microbial growth on mixtures of substitutable substrates in a chemostat. J Theor Biol. 1998;190:241-61.

114. Jiang Y, Chen F. Effects of temperature and temperature shift on docosahexaenoic acid production by the microalga Crypthecodinium cohnii. J Am Oil Chem Soc. 2000;77:613-7.

115. Li X, Pei G, Liu L, Chen L, Zhang W. Metabolomic analysis and lipid accumulation in a glucose tolerant Crypthecodinium cohnii strain obtained by adaptive laboratory evolution. Bioresour Technol. 2017;235:87-95.

116. Kurosawa K, Radek A, Plassmeier JK, Sinskey AJ. Improved glycerol utilization by a triacylglycerol-producing Rhodococcus opacus strain for renewable fuels. Biotechnol Biofuels. 2015;8:1-11.

117. Yoneda A, Henson WR, Goldner NK, Park KJ, Forsberg KJ, Kim SJ, Pesesky MW, Foston M, Dantas G, Moom TS. Comparative transcriptomics elucidates adaptive phenol tolerance and utilization in lipid-accumulating Rhodococcus opacus PD630. Nucleic Acids Res. 2016;44:2240-54.

118. Yu SY, Zhao QY, Miao XL, Shi JP. Enhancement of lipid production in low-starch mutants Chlamydomonas reinhardtii by adaptive laboratory evolution. Bioresour Technol. 2013;147:499-507.

119. Fu W, Gudmundsson O, Feist AM, Herjolfsson G, Brynjolfsson S, Palsson $\mathrm{B} \emptyset$. Maximizing biomass productivity and cell density of Chlorella vulgaris by using light-emitting diode-based photobioreactor. J Biotechnol. 2012;161:242-9.

120. Fu W, Ólafur G, Giuseppe P, Gísli H, Andrésson ÓS, Palsson BØ, Sigurður B. Enhancement of carotenoid biosynthesis in the green microalga Dunaliella salina with light-emitting diodes and adaptive laboratory evolution. Appl Microbiol Biotechnol. 2013;97:2395-403.

121. Fu W, Paglia G, Magnúsdóttir M, Steinarsdóttir EA, Gudmundsson S, Palsson BØ, Andrésson ÓS, Brynjólfsson S. Effects of abiotic stressors on lutein production in the green microalga Dunaliella salina. Microb Cell Fact. 2014;13:1-9

122. Yi Z, Xu M, Magnusdottir M, Zhang Y, Brynjolfsson S, Fu W. Photo-oxidative stress-driven mutagenesis and adaptive evolution on the marine diatom Phaeodacty/um tricornutum for enhanced carotenoid accumulation. Mar Drugs. 2015;13:6138-51.

123. Li D, Wang L, Zhao Q, Wei W, Sun Y. Improving high carbon dioxide tolerance and carbon dioxide fixation capability of Chlorella sp. by adaptive laboratory evolution. Bioresour Technol. 2015;185:269-75.

124. Cheng J, Li K, Yang Z, Lu H, Zhou J, Cen K. Gradient domestication of Haematococcus pluvialis mutant with $15 \% \mathrm{CO}^{2}$ to promote biomass growth and astaxanthin yield. Bioresour Technol. 2016;216:340-4.

125. Perrineau MM, Zelzion E, Gross J, Price DC, Boyd J, Bhattacharya D. Evolution of salt tolerance in a laboratory reared population of Chlamydomonas reinhardtii. Environ Microbiol. 2014;16:1755-66.

126. Siaut M, Cuiné S, Cagnon C, Fessler B, Mai N, Carrier P, Beyly A, Beisson F, Triantaphylidès C, Li-Beisson Y, Peltier G. Oil accumulation in the model green alga Chlamydomonas reinhardtii: characterization, variability between common laboratory strains and relationship with starch reserves. BMC Biotechnol. 2011;11:7.

127. Kato Y, Ho SH, Vavricka CJ, Chang JS, Hasunuma T, Kondo A. Evolutionary engineering of salt-resistant Chlamydomonas sp strains reveals salinity stress-activated starch-to-lipid biosynthesis switching. Bioresour Technol. 2017;245:1484-90. 
128. Sun XM, Ren LJ, Bi ZQ, Ji XJ, Zhao QY, Huang H. Adaptive evolution of microalgae Schizochytrium sp. under high salinity stress to alleviate oxidative damage and improve lipid biosynthesis. Bioresour Technol. 2018;267:438-44.

129. Tzovenis I, Pauw ND, Sorgeloos P. Effect of different light regimes on the docosahexaenoic acid (DHA) content of Isochrysis aff. galbana (clone T-ISO). Aquacult Int. 1997;5:489-507.

130. Richard D, Kefi K, Barbe U, Bausero P, Visioli F. Polyunsaturated fatty acids as antioxidants. Photosynth Res. 2008:57:451-5.

131. Sun XM, Ren LJ, Ji XJ, Chen SL, Guo DS, Huang H. Adaptive evolution of Schizochytrium sp. by continuous high oxygen stimulations to enhance docosahexaenoic acid synthesis. Bioresour Technol. 2016;211:374-81.

132. Osundeko O, Davies H, Pittman JK. Oxidative stress-tolerant microalgae strains are highly efficient for biofuel feedstock production on wastewater. Biomass Bioenergy. 2013;56:284-94.

133. Sun XM, Ren LJ, Bi ZQ, Ji XJ, Zhao QY, Jiang L, Huang H. Development of a cooperative two-factor adaptive-evolution method to enhance lipid production and prevent lipid peroxidation in Schizochytrium sp. Biotechnol Biofuels. 2018;11:65.

134. Shin SE, Koh HG, Kang NK, Suh WI, Jeong B, Lee B, Chang YK. Isolation, phenotypic characterization and genome wide analysis of a Chlamydomonas reinhardtii strain naturally modified under laboratory conditions: towards enhanced microalgal biomass and lipid production for biofuels. Biotechnol Biofuels. 2017;10:308.

135. Perrineau MM, Gross J, Zelzion E, Price DC, Levitan O, Boyd J, Bhattacharya D. Using natural selection to explore the adaptive potential of Chlamydomonas reinhardtii. PLoS ONE. 2014;9:e92533.

136. Uchiyama J, Kanesaki Y, Iwata N, Asakura R, Funamizu K, Tasaki R, Agatsuma M, Tahara H, Matsuhashi A, Yoshikawa H, Ogawa S, Ohta H. Genomic analysis of parallel-evolved cyanobacterium Synechocystis sp. PCC 6803 under acid stress. Photosynth Res. 2015:125:243-54.

137. Tillich UM, Wolter N, Franke P, Dühring U, Frohme M. Screening and genetic characterization of thermo-tolerant Synechocystis sp. PCC 6803 strains created by adaptive evolution. BMC Biotechnol. 2014;14:1-15.

138. Wang Y, Shi M, Niu X, Zhang X, Gao L, Chen L, Wang J, Zhang W. Metabolomic basis of laboratory evolution of butanol tolerance in photosynthetic Synechocystis sp. PCC 6803. Microb Cell Fact. 2014;13:151.

139. Singh J, Gu S. Commercialization potential of microalgae for biofuels production. Renew Sustain Energy Rev. 2010;14:2596-610.

140. Zhang S, He YD, Sen B, Chen XH, Xie YX, Keasling JD, Wang G. Alleviation of reactive oxygen species enhances PUFA accumulation in Schizochytrium sp. through regulating genes involved in lipid metabolism. Metab Eng Commun. 2018;6:39-48.
Ready to submit your research? Choose BMC and benefit from:

- fast, convenient online submission

- thorough peer review by experienced researchers in your field

- rapid publication on acceptance

- support for research data, including large and complex data types

- gold Open Access which fosters wider collaboration and increased citations

- maximum visibility for your research: over 100M website views per year

At BMC, research is always in progress.

Learn more biomedcentral.com/submissions 